\title{
Platelet-rich plasma (PRP) to treat chronic patellar tendinopathies: comparison of a single versus two closely-timed injections
}

\author{
Jean-François Kaux ${ }^{1}$ \\ Vincent Libertiaux ${ }^{2}$ \\ Jean-Louis Croisier ${ }^{3}$ \\ Jean-Michel Crielaard ${ }^{1}$
}

1 Department of Physical Medicine and Sports Traumatology, CHU Liège, Belgium

2 Department of Clinical Sciences, Faculty of Veterinary Medicine, University of Liège, Belgium

3 Department of Sports and Rehabilitation Sciences, University of Liège, Belgium

\section{Corresponding author:}

Jean-François Kaux

Department of Physical Medicine and Sports Traumatology, CHU Liège, Avenue de l'Hôpital

Avenue de l'Hôpital B35, 4000 Liége, Belgium

E-mail: jfkaux@chu.ulg.ac.be

\section{Dear Editor,}

we have read with attention the article by Zayni et al. ${ }^{1}$ comparing the effect of 1 or 2 weekly PRP injection(s) whose conclusions are opposed to the findings of our previously published study ${ }^{2}$. Indeed, they observed that 2 injections lead to better results than only 1, but our data suggested that a single injection is sufficient to obtain the same results. The populations in the 2 studies seem to be not exactly similar at baseline, but perhaps the number of injections should be tailored to severity. However this statement must still to be demonstrated. Beside the number of injections, other differences are observed in the experimental protocol. Zayni et al. used the ACP system which expect to produce a PRP with platelet concentration twice as high as in whole blood and without leukocytes. The PRP in our study was obtained using an apheresis machine capable of extracting a reproducible platelet concentration of 850,000 units/microlitre (+/- 4 times as high as whole blood) and without white or red cells. The number of platelets obtained in the injected PRP is very important. Indeed, platelet secretome is composed of hundreds of molecules, and on the basis of $\alpha$ granule content, PRP platelets contain proteins with opposing activities: coagulation factors and anticoagulants; proteins that encourage and those that discourage angiogenesis; and proteases and their inhibitors. Thus to standardize and to understand the efficacy of the $\mathrm{PRP}^{3}$, it could be helpful to have exactly the same platelet concentration, as obtained with the aphaeresis machine, but not with the ACP system. The injection method (under ultrasound guidance) was comparable in both studies but the platelet activation by $\mathrm{CaCl}_{2}$, to activate the platelets, leading to their degranulation, was triggered only in ours.

Despite both studies prescribed an eccentric rehabilitation protocol ${ }^{4}$, the starting points differed: Zayni et al. recommended to wait a period of 2 weeks while we started it as soon as the painful period was finished. Finally, the best obtained results were similar in the 2 reports, with a 2 years follow-up in the Zayni et al. series and 1 year in our study.

Zayni et al. protocol was based on the preclinical research by Parafioriti et al. ${ }^{5}$ who observed in the rat model that a single PRP injection in Achilles tendon tear had a limited effectiveness and its effect dissipates after one week. However, our preclinical study on rats showed that PRP injection not only leads to a better early enhancement of the healing process but also to a better tendon structure up to 1 month after injection ${ }^{6}$.

From this comparison, it seems that the key factor to a successful healing is the platelets concentration. Indeed, since our best results are comparable to Zayni's, a platelet concentration 4 times as high as whole blood is needed, either in one or multiple injections. The apheresis machine also enables the reproducibility of the PRP preparation ${ }^{7}$, producing every time the same platelet concentration, whatever the patient whole blood initial concentration. This is not true for the ACP system, for which the platelet concentration varies with respect to its natural concentration in the patients' whole blood, as demonstrated by the analysis of similar PRP preparation techniques ${ }^{8,9}$. Furthermore, the multiplication of injections increases the risk of complications, the treatment price and the patient discomfort, having to go multiple times to the doctor or hospital ${ }^{10}$. In conclusion, the number of injections of PRP needed to obtain good clinical results can vary depending of the quality of the PRP used or, perhaps, of the severity of the tendinopathy. Further well-standardized studies remain necessary, according to the recommendations of the Journal11.

\section{References}

1. Zayni R, Thaunat M, Fayard JM, Hager JP, Carrillon Y, Clechet $\mathrm{J}$, et al. Platelet-rich plasma as a treatment for chronic patellar tendinopathy: comparison of a single versus two consecutive injections. Muscles Ligaments Tendons J. 2015;5(2):92-8. 
2. Kaux JF, Croisier JL, Forthomme B, Le Goff C, Buhler F, Savanier $\mathrm{B}$, et al. Using platelet-rich plasma to treat jumper's knees: Exploring the effect of a second closely-timed infiltration. J Sci Med Sport. 2015.

3. Kaux JF, Drion P, Croisier JL, Crielaard JM. Tendinopathies and platelet-rich plasma (PRP): From preclinical experiments to therapeutic use. J Stem Cells Regen Med. 2015;11:P7-P17.

4. Kaux JF, Forthomme B, Namurois MH, Bauvir P, Defawe N, Delvaux $F$, et al. Description of a standardized rehabilitation program based on sub-maximal eccentric following a plateletrich plasma infiltration for jumper's knee. Muscles Ligaments Tendons J. 2014;4(1):85-89.

5. Parafioriti A, Armiraglio E, Del Bianco S, Tibalt E, Oliva F, Berardi AC. Single injection of platelet-rich plasma in a rat Achilles tendon tear model. Muscles Ligaments Tendons J. 2011; 1(2):41-47.

6. Kaux JF, Drion PV, Colige A, Pascon F, Libertiaux V, Hoffmann $A$, et al. Effects of platelet-rich plasma (PRP) on the healing of Achilles tendons of rats. Wound Repair Regen. 2012;20(5):748-756.
7. Moog R, Franck V, Pierce JA, Müller N. Evaluation of a concurrent multicomponent collection system for the collection and storage of WBC-reduced RBC apheresis concentrates. Transfusion. 2001;41(9):1159-1164.

8. Kaux JF, Le Goff C, Seidel L, Péters P, Gothot A, Albert A, et al. Comparative study of five techniques of preparation of platelet-rich plasma. Pathol Biol (Paris). 2011;59(3):157160.

9. Kaux JF, Le Goff C, Renouf J, Peters P, Lutteri L, Gothot A, et al. Comparison of the platelet concentrations obtained in platelet-rich plasma (PRP) between the GPS ${ }^{\mathrm{TM}}$ II and GPS $^{\mathrm{TM}}$ III systems. Pathol Biol (Paris). 2011;59(5):275-277.

10. Kaux JF, Bouvard M, Lecut C, Oury C, Gothot A, Sanchez M, et al. Reflections about the optimisation of the treatment of tendinopathies with PRP. Muscles Ligaments Tendons J. $2015 ; 5(1): 1-4$

11. Padulo J, Oliva F, Frizziero A, Maffulli N. Muscles, Ligaments and Tendons Journal. Basic principles and recommendations in clinical and field science research. MLTJ. 2013;4:250-252. 